\title{
Neuroanatomy of Stress Responses
}

\author{
Takashi Ueyama* \\ Department of Anatomy and Cell Biology, Wakayama Medical University Graduate School of Medicine, Kimiidera, \\ Wakayama, Japan
}

\begin{abstract}
The autonomic nervous system, especially the sympathetic nervous system, regulates immune responses, while cytokines produced in the immune system also affect neuronal activities. Stress-induced expression of immediate early genes, such as c-Fos in the brain, and the viral transneuronal labeling using pseudorabies virus make it possible to analyze the neurocircuitry of the stress-related central autonomic nervous system. Limbic systems (amygdala, lateral septum, infralimbic, insular, ventromedial temporal cortical regions), and several hypothalamic and brainstem nuclei have been identified as the central sites that regulate stress-induced sympathetic nervous activation. This review focuses on the involvement of the amygdala in the regulation of stress-induced sympathetic nervous responses. All amygdaloid subnuclei receive psychological information from other limbic regions, while the lateral and central subnuclei receive sensory and immune information from parabrachial nucleus and medical geniculate nucleus. Output to the hypothalamus mainly originates from the medial amygdala, while output to the bed nucleus of the stria terminalis originates from the central amygdala and the medial amygdala. Sex steroids such as estrogen and androgen can modulate the sympathetic nervous activity since their receptors are expressed in the medial amygdala.
\end{abstract}

Keywords: Amygdala, central autonomic nervous system, immediate early genes, projection, sex steroids, viral trans-neuronal labeling

\section{ABBREVIATIONS}

A5

A7

A5 noradrenaline cells

AA anterior amygdaloid area

Acb accumbens nucleus

AcbC accumbens nucleus, core

AcbSh accumbens nucleus, shell

ACo anterior cortical amygdaloid nucleus

$\mathrm{AH}$ anterior hypothalamic area

AHi amygdalohippocampal area

AHiAL amygdalohippocampal area, anterolateral part

AHiPM amygdalohippocampal area, posteromedial part

\footnotetext{
${ }^{*}$ Correspondence to: Takashi Ueyama, M.D., Ph.D., Department of Anatomy and Cell Biology, Wakayama Medical University Graduate School of Medicine, 811-1, Kimiidera, Wakayama, 641-8509, Japan. Tel./Fax: +81 73441 0616; E-mail: tueyama@wakayamamed.ac.jp.
}

$\begin{array}{ll}\text { AI } & \text { agranular insular cortex } \\ \text { AP } & \text { area postrema } \\ \text { APir } & \begin{array}{l}\text { amygdalopiriform transition area } \\ \text { Arc }\end{array} \\ \text { BAOT } & \begin{array}{l}\text { bed nucle hypothalamic nucleus } \\ \text { basolateral amygdaloid nucleus }\end{array} \\ \text { BL } & \text { basolateral amygdaloid nucleus, anterior } \\ \text { BLA } & \text { part } \\ \text { BLP } & \begin{array}{l}\text { basolateral amygdaloid nucleus, posterior } \\ \text { part }\end{array} \\ \text { BLV } & \begin{array}{l}\text { basolateral amygdaloid nucleus, ventral } \\ \text { part }\end{array} \\ \text { BM } & \begin{array}{l}\text { basomedial amygdaloid nucleus } \\ \text { basomedial amygdaloid nucleus, anterior }\end{array} \\ \text { BMA } & \begin{array}{l}\text { part } \\ \text { basomedial amygdaloid nucleus, posterior }\end{array} \\ \text { BMP } & \text { part } \\ \text { BST } & \begin{array}{l}\text { bed nucleus of the stria terminalis } \\ \text { bed nucleus of the stria terminalis, }\end{array} \\ \text { BSTIA } & \begin{array}{l}\text { intraamygdaloid division } \\ \text { field CA1 of the hippocampus }\end{array} \\ \text { CA1 } & \end{array}$




\begin{tabular}{|c|c|c|c|}
\hline $\mathrm{CA} 2$ & field CA2 of the hippocampus & LPMR & lateral posterior thalamic nucleus, \\
\hline $\mathrm{CeA}$ & central amyodaloid nucleus & LPO & lateral preoptic area \\
\hline $\mathrm{CeC}$ & central amygdaloid nucleus, capsular part & $\mathrm{LS}$ & lateral septal nucleus \\
\hline $\mathrm{CeL}$ & central amygdaloid nucleus, lateral division & LSD & lateral septal nucleus, dorsal part \\
\hline \multirow[t]{2}{*}{ CeM } & central amygdaloid nucleus, medial & LSI & lateral septal nucleus, intermediate part \\
\hline & division & LSV & lateral septal nucleus, ventral part \\
\hline $\mathrm{Cgl}$ & cingulate cortex, area 1 & M1 & primary motor cortex \\
\hline $\mathrm{CM}$ & central medial thalamic nucleus & M2 & secondary motor cortex \\
\hline $\mathrm{CPu}$ & caudate putamen (striatum) & MCPO & magnocellular preoptic nucleus \\
\hline $\mathrm{CoA}$ & cortical amygdaloid nucleus & MD & mediodorsal thalamic nucleus \\
\hline CxA & cortex-amygdala transition zone & $\mathrm{MeA}$ & medial amygdaloid nucleus \\
\hline DEn & dorsal endopiriform nucleus & MeAD & medial amygdaloid nucleus, anterodorsal \\
\hline DLL & dorsal nucleus of the lateral lemniscus & & part \\
\hline DLPAG & dorsolateral periaqueductal gray & MeAV & medial amygdaloid nucleus, anteroventral \\
\hline DMH & dorsomedial hypothalamic nucleus & & part \\
\hline DMPAG & dorsomedial periaqueductal gray & MePD & medial amygdaloid nucleus, posterodorsal \\
\hline DP & dorsal peduncular cortex & & part \\
\hline DpMe & deep mesencephalic nucleus & MePV & medial amygdaloid nucleus, posteroventral \\
\hline DR & dorsal raphe nucleus & & part \\
\hline DRC & dorsal raphe nucleus, caudal part & MG & medial geniculate nucleus \\
\hline DRD & dorsal raphe nucleus, dorsal part & MGD & medial geniculate nucleus, dorsal part \\
\hline DTgP & dorsal tegmental nucleus, pericentral part & MGM & medial geniculate nucleus, medial part \\
\hline Ect & ectorhinal cortex & $\mathrm{MHb}$ & medial habenular nucleus \\
\hline Eth & ethmoid thalamic nucleus & MM & medial mammillary nucleus, medial part \\
\hline EW & Edinger-Westphal nucleus & MO & medial orbital cortex \\
\hline \multirow[t]{2}{*}{$\mathrm{GiV}$} & gigantocellular reticular nucleus, ventral & MPA & medial preoptic area \\
\hline & ( & MPB & medial parabrachial nucleus \\
\hline \multirow[t]{2}{*}{ HDB } & nucleus of the horizontal limb of the & MPO & medial preoptic nucleus \\
\hline & diagonal band & MS & medial septal nucleus \\
\hline IAM & interanteromedial thalamic nucleus & NTS & nucleus of the solitary tract \\
\hline IL & infralimbic cortex & opt & optic tract \\
\hline $\mathrm{IM}$ & $\begin{array}{l}\text { intercalated amygdaloid nucleus, } \\
\text { main part }\end{array}$ & $\mathrm{PaAP}$ & $\begin{array}{l}\text { parventricular hypothalamic nucleus, } \\
\text { anterior parvicellular part }\end{array}$ \\
\hline \multirow[t]{2}{*}{ IPAC } & interstitial nucleus of the posterior limb of & PB & parabrachial nucleus \\
\hline & the anterior commissure & $\mathrm{Pe}$ & periventricular hypothalamic nucleus \\
\hline $\mathrm{LaA}$ & lateral amygdaloid nucleus & $\mathrm{PeF}$ & perifornical nucleus \\
\hline \multirow[t]{2}{*}{$\mathrm{LaDL}$} & lateral amygdaloid nucleus, dorsolateral & $\mathrm{PF}$ & parafascicular thalamic nucleus \\
\hline & part & $\mathrm{PH}$ & posterior hypothalamic area \\
\hline $\mathrm{LaVL}$ & lateral amygdaloid nucleus, ventrolateral & PIL & posterior intralaminar thalamic nucleus \\
\hline & part & Pir & piriform cortex \\
\hline LaVM & $\begin{array}{l}\text { lateral amygdaloid nucleus, ventromedial } \\
\text { part }\end{array}$ & PLCo & $\begin{array}{l}\text { posterolateral cortical amygdaloid } \\
\text { nucleus }\end{array}$ \\
\hline $\mathrm{LC}$ & locus coeruleus & PMCo & posteromedial cortical amygdaloid nucleus \\
\hline LDTg & laterodorsal tegmental nucleus & PMD & premammillary nucleus, dorsal part \\
\hline LEnt & lateral entorhinal cortex & PMV & premammillary nucleus, ventral part \\
\hline LH & lateral hypothalamic area & $\mathrm{PP}$ & peripeduncular nucleus \\
\hline LO & lateral orbital cortex & $\mathrm{PRh}$ & perirhinal cortex \\
\hline LPAG & lateral periaqueductal gray & PrL & prelimbic cortex \\
\hline LPB & lateral parabrachial nucleus & PSTh & parasubthalamic nucleus \\
\hline LPGi & lateral paragigantocellular nucleus & PT & paratenial thalamic nucleus \\
\hline
\end{tabular}


PV paraventricular thalamic nucleus

PVA paraventricular thalamic nucleus, anterior part

PVH paraventricular hypothalamic nucleus

PVP paraventricular thalamic nucleus, posterior part

$\mathrm{RCh}$ retrochiasmatic area

REth retroethmoid nucleus

$\mathrm{RMg}$ raphe magnus nucleus

$\mathrm{RPa}$ raphe pallidus nucleus

RVL rostroventrolateral reticular nucleus

S subiculum

S1 primary somatosensory cortex

S2 secondary somatosensory cortex

SCN suprachiasmatic nucleus

SI substantia innominata

SO supraoptic nucleus

SPFPC subparafascicular thalamic nucleus, parvicellular part

SubB subbrachial nucleus

SuM supramammillary nucleus

TeA temporal association cortex

Tu olfactory tubercle

VC ventral cochlear nucleus

VDB nucleus of the ventral limb of the diagonal band

VEn ventral endopiriform nucleus

VLPAG ventrolateral periaqueductal gray

VMH ventromedial hypothalamic nucleus

VP ventral pallidum

VPL ventral posterolateral thalamic nucleus

VTM ventral tuberomammilary nucleus

ZI zona incerta

\section{INTRODUCTION}

Bidirectional interactions between the autonomic nervous system (sympathetic nervous system and parasympathetic nervous system) and the immune system have been studied extensively. The immune system is regulated mainly by the sympathetic nervous system, and sympathetic postganglionic neurons innervate all primary and secondary immune organs substantially [1]. Thus, the primary pathway for neural regulation of immune function is the sympathetic nervous system and its main neurotransmitter, norepinephrine (NE). Innate immune cells express both $\alpha$ and $\beta$-adrenergic receptor subtypes, while $\mathrm{T}$ and $\mathrm{B}$ lymphocytes express adrenergic receptors of the $\beta 2$ subtype exclusively [1]. Activation of these adrenergic receptors induces vari- ous changes in cellular signaling pathways, resulting in alterations of gene expression for cytokines and antibodies. Recently, the involvement of the parasympathetic nervous system on immune regulation has been also reported. For example, stimulation of the vagus nerve attenuates cytokine production, thereby improving survival in experimental sepsis, hemorrhagic shock, ischemia-reperfusion injury, and other conditions of cytokine excess [2]. Proinflammatory cytokines such as interleukin-1 $\beta$ (IL-1 $\beta$ ), tumor necrosis factor- $\alpha$ (TNF- $\alpha)$ and interleukin-6 (IL-6) and other chemical mediators produced in the immune systems also affect neuronal activities. Cytokines and their receptors are expressed in the nervous systems, and may be attributed to invading immune, or resident cells [3, 4]. Neuronal immune-modulations are conducted within the central nervous system (CNS). For instance, neural activity of the amygdala and insular cortex as measured by implanted deep-brain electrodes is not only specific for the type of immune challenge (T-cell-independent antigen lipopolysaccharide versus the T-cell-dependent antigen staphylococcal enterotoxin B), but also sensitive to different immune states (naive versus desensitization) [5].

The first purpose of this review is to introduce recent advances in central autonomic nervous system that regulates the peripheral sympathetic nervous system by a comparison of the data from different kinds of neuroanatomical labeling techniques. The second purpose of this review is to reinvestigate and summarize the exra- and intra-amygdala projections into major subnuclei of the amygdala, a key-relay and integrative region of the central autonomic nervous system, and projections from the medical amygdaloid nucleus and from the central amydgaloid nucleus.

\section{CENTRAL AUTONOMIC NERVOUS SYSTEM}

The peripheral autonomic nervous system (sympathetic postganglionic neurons and parasympathetic postganglionic neurons) is regulated or sequentially innervated by the CNS. Neuroanatomical methods, using retrograde traces such as Cholera toxin B subunit $(\mathrm{CTb})$ and anterograde traces such as Phaesolus vulgaris-leucoagglutinin (PHAL), have revealed the anatomical neuronal connections. The introduction of trans-neuronal tracers has helped clarify the sequentially innervated CNS. The Bartha strain of 
pseudorabies virus (PRV) has been shown to be useful for the analysis of the CNS in the rat [6].

Emotional stress and physical stress activate the peripheral and central autonomic nervous system. These activated neurons can be detected by monitoring the expression of immediate early genes such as c-Fos [7]. Immobilization stress (IMO) in the rat is an excellent model of emotional stress, which activates the hypothalamic-pituitary-adrenocortical system and the sympathoadrenal system [8]. Increased numbers of cFos immunoreactive (IR) cells in response to IMO have been observed in cerebral cortex, septum, thalamus, hypothalamus, midbrain, pons and medulla oblongata $[7,9]$. Each section in the left panel of Fig. 1 indicates the regions where increases in c-Fos IR in response to IMO were observed, while each section in the central panel of Fig. 1 indicates the central sites linked to the sympathoadrenal system. By comparison of c-Fos mapping, PRV mapping and other neuronal tracing, the central autonomic nervous system can be demonstrated.

Neurons in the CNS that are labeled in a retrograde trans-neuronal fashion from sympathetic ganglion and adrenal medulla include the following [10-12]: rostroventrolateral reticular nucleus, ventral gigantocellular reticular nucleus, lateral paragigantocellular nucleus, nucleus of the solitary tract, area postrema, raphe pallidus nucleus, raphe magnus nucleus, A5 noradrenaline cells, A7 noradrenaline cells, laterodorsal tegmental nucleus, locus coeruleus, periaqueductal gray, dorsal raphe nucleus, parabrachial nucleus, hypothalamic nuclei, medial habenular nucleus, zona incerta, paraventricular thalamic nucleus, piriform cortex, amygdaloid nuclei, amygdalohippocampal area, field CA1 of the hippocampus, lateral septal nucleus, accumbens nucleus, bed nucleus of the stria terminalis, dorsal peduncular cortex, dorsal endopiriform nucleus, infralimbic cortex and agranular insular cortex. In particular, the neurons in the medial amygdaloid nucleus, field CA1 of the hippocampus, amygdalohippocampal area, dorsal endopiriform nucleus, agranular insular cortex and infralimbic cortex are heavily labeled. As shown in Fig. 1, c-Fos-increased regions and PRV-positive regions overlap, suggesting that neurons located in these regions are probably involved in sympathoadrenal outflow in response to stress.

Each section in the right panel of Fig. 1 indicates the regions that are labeled in a retrograde fashion following injection of $\mathrm{CTb}$ into the medial amygdaloid nucleus, and are those which project into the medial amygdaloid nucleus. The affer- ent projections into the medial amygdaloid nucleus include the ipsilateral agranular insular cortex, piriform cortex, infralimbic cortex, lateral septal nucleus, dorsal endopiriform nucleus, bed nucleus of the stria terminalis, basomedial amygdaloid nucleus, cortical amydgaloid nucleus, amydalopiriform transition area, amygdalohippocampal area, field CA1 of the hippocampus and zona incerta. Neurons in the cortical amydgaloid nucleus, amydalopiriform transitional area, amygdalohippocampal area, ventral field CA1 of the hippocampus, agranular insular cortex, and piriform cortex are heavily labeled. These regions overlap with the PRV-positive regions except for

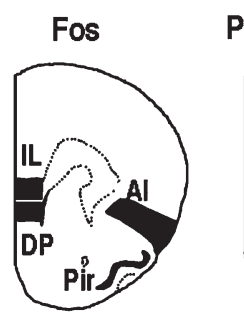

PRV into SymG

CTb into MeA
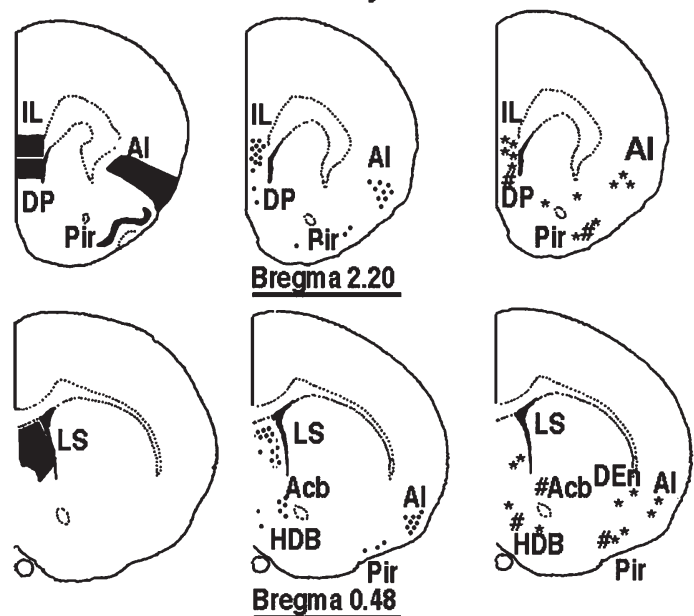

Bregma 0.48
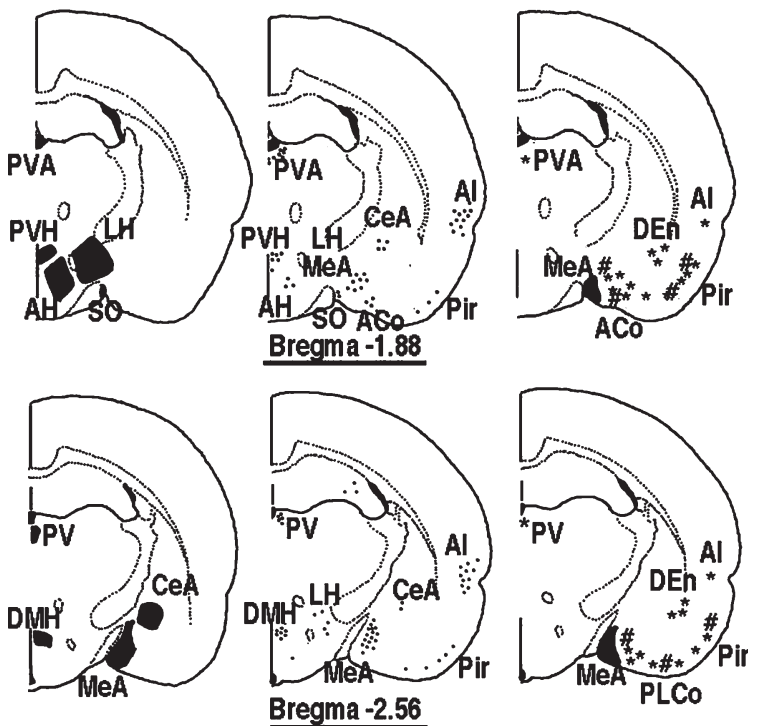

Fig. 1. (Continued) 
Fos $\quad$ PRV into SymG CTb into MeA
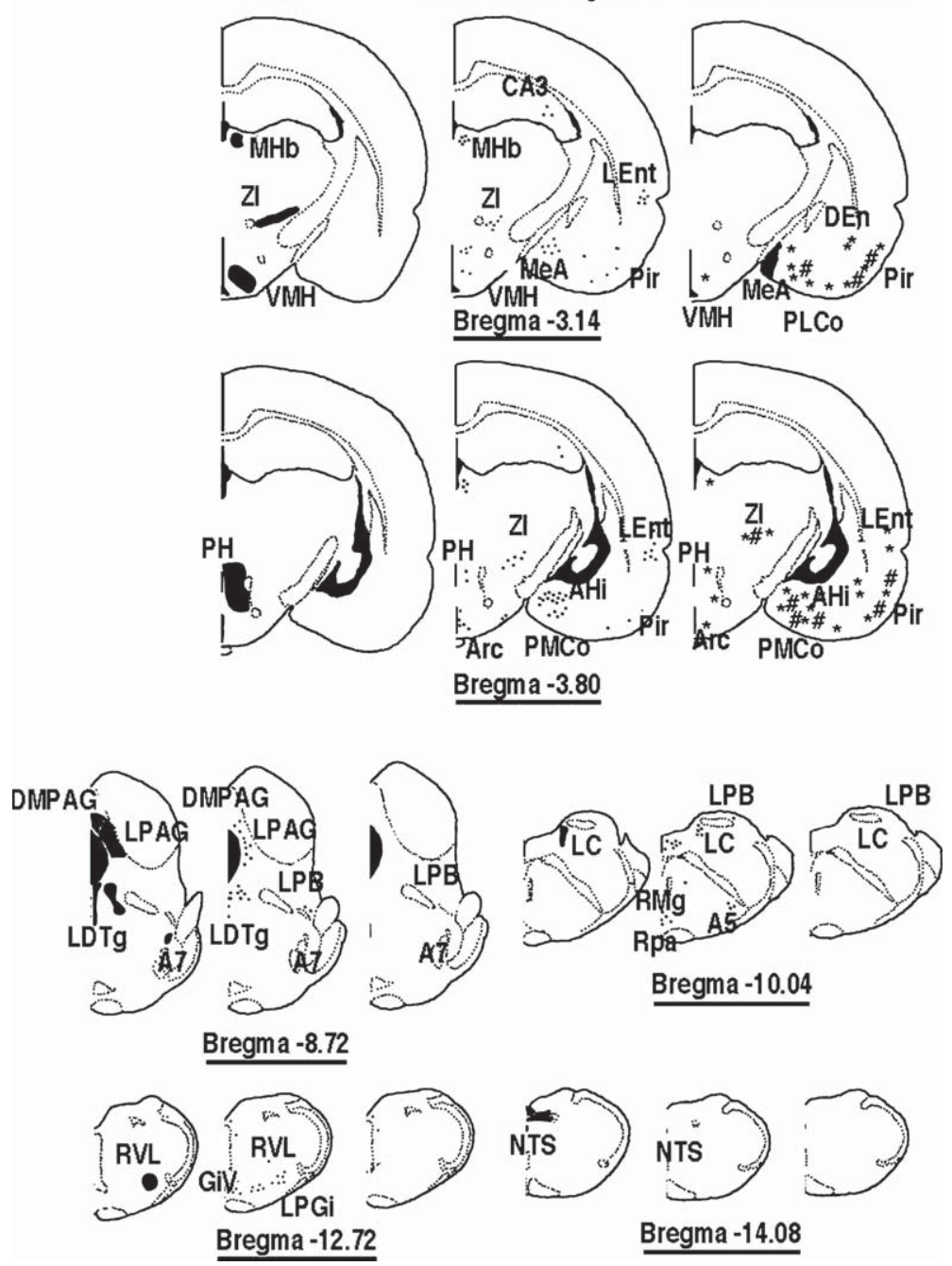

Fig. 1. Distribution of the central autonomic nervous system that is reactive to emotional stress. (A) The left panels are the coronal sections of the rat brain showing the regions where significant expression of c-Fos was observed in response to IMO. Adult female Wistar rats were exposed to immobilization stress (IMO) for 2 hours'DThe brains were fixed with $4 \%$ paraformaldehyde in $0.1 \mathrm{M}$ sodium phosphate buffer (pH 7.4), followed by immunohistochemical detection of c-Fos (rabbit anti c-Fos serum, Oncogene Science, Ab-5, diluted 1:10,000 with 0.1 M PBS containing 5\% normal goat serum). (B) The central panels are the coronal sections of the rat brain showing the central autonomic neurons as revealed by infection of pseudorabies virus (PRV) to the peripheral sympathetic ganglion or adrenal medulla. The Bartha strain of PRV (50 nl; titer $=10^{8}$ plaque forming unit $/ \mathrm{ml}$ ) was injected to the adrenal medulla or stellate ganglion of adult male Sprague-Dawley rats. After 8 days, the brains were fixed, followed by immunohistochemical detection of PRV (Pig-anti PRV provided by Dr. KB Platt, Iowa State University, Ames, IA, USA; diluted 1:25,000 with $0.1 \mathrm{~m}$ PBS containing 5\% normal donkey serum). (C) The right panels are the coronal sections of the rat brain showing the afferent projection to the medial amygdaloid nucleus. $\mathrm{CTb}$ (1\% solution in distilled water; List Biological Laboratories Inc. Campbell, CA, USA) was applied iontophoretically using $5.5 \mu \mathrm{A}$ on/off positive current to the medial amygdaloid nucleus of adult female Wistar rats based on coordinates from a rat brain atlas [23]. After 7 days, the rats were exposed to IMO for 2 hours. The brains were fixed, followed by double-immunohistochemical detection of CTb (goat anti-CTb, List Biological Laboratories Inc., diluted with 1:20,000 with 0.1 M PBS containing 5\% normal donkey serum) and c-Fos. * indicates the regions with CTb-single positive, \# indicates the regions with $\mathrm{CTb}$ - and c-Fos-double positive. (Panels A, B and C reprinted from reference 43 with permission).

the hypothalamic nuclei and brain stem nuclei. In addition, double-positive neurons with both $\mathrm{CTb}$ and c-Fos are observed in these regions except for field CA1 of the hippocampus and dorsal endopiriform nucleus. Many double-positive neurons were observed in the basomedial amygdaloid nucleus and cortical amydgaloid nucleus as shown in Fig. 2. 

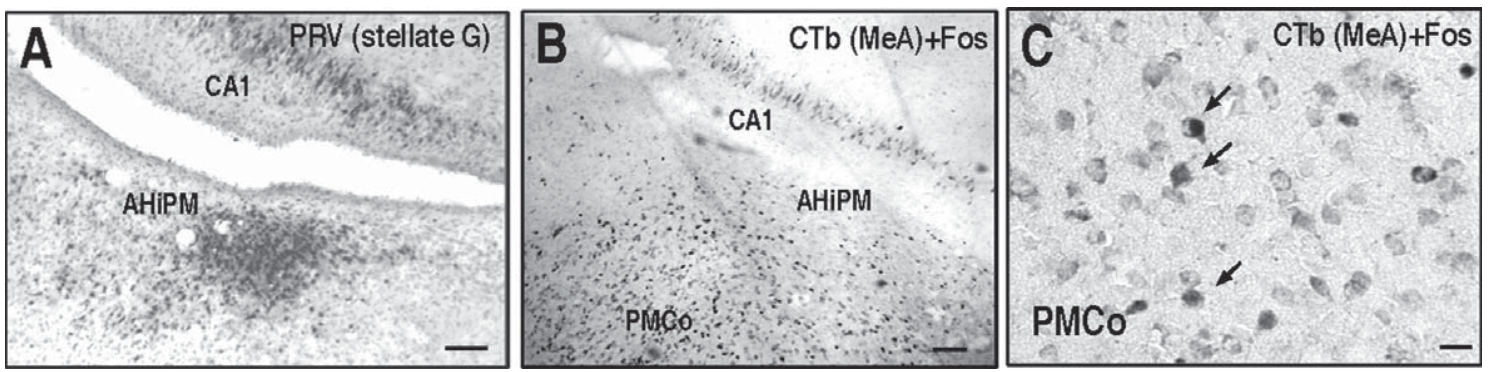

Fig. 2. Central autonomic neurons reactive to stress in the amygdalohippocampal area and the cortical amygdaloid nucleus. (A) Strong PRV labeling in field CA1 of the hippocampus and amygdalohippocampal area following injection of RRV into the stellate ganglion. (B, C) The arrows indicate co-localization of $\mathrm{CTb}$ and c-Fos in field CA1 of the hippocampus, amygdalohippocampal area and cortical amygdaloid nucleus

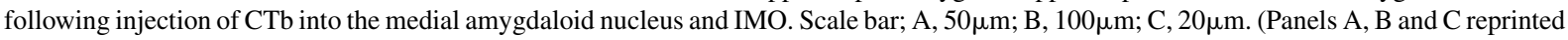
from reference 43 with permission).

Taken together, the results suggest that the amygdala is the key region that relays and integrates stressresponsive information from the higher limbic brain to hypothalamic nuclei, brain stem nuclei, and peripheral sympathetic nervous system.

\section{THE SUBNUCLEI IN THE AMYGDALA}

The amygdala is a small almond-shaped structure located in the temporal lobe. The amygdala has been reviewed repeatedly because it is implicated strongly in emotional processes [13-21]. The amygdala is a key region that integrates both input and output to the peripheral autonomic nervous system and the higher limbic system. The amygdala is also involved in the immune response [5, 22].

The amygdaloid complex is diverse structurally, and is comprised of approximately 13 nuclei [16]. These are divided further into subdivisions that have extensive internuclear and intranuclear connections. These nuclei and subnuclei are distinguished on the basis of cytoarchitectonics, histochemistry, and the connections they make [16]. The architectonic organization and connectivity of the amygdala have been reviewed extensively [14, 17, 20, 21]. For instance, Price [14] identified three distinct groups of nuclei connected differently with other brain structures. First, the basolateral group, also called the group of deep nuclei, is composed of the lateral, basal, and basomedial nuclei (basomedial nucleus is also termed the accessory basal nucleus), and is characterized by substantial interconnections with the neocortex. Second is the corticomedial or superficial group, which is made up of periamygdaloid cortex, the anterior and posterior cortical nuclei, the medial nucleus, and the nucleus of the lateral olfactory tract, and is connected directly with the olfactory and accessory olfactory system. The third group of nuclei is composed of the central nucleus and the anterior amygdaloid area, which are strongly interconnected with the autonomic control centers in the lateral hypothalamus and the brain stem structures. McDonald [17], as well as Swanson and Petrovich [18] have further developed the partition introduced by Price [14]. They divided the amygdala into three parts: 1) the deep or basolateral group, which included a ventromedial extension of the deepest layer of the cortex (the lateral, basal, and basomedial nuclei); 2) the centromedial group, which is a specialized ventromedial expansion of the striatum (the central and medial nuclei, as well as the amygdaloid part of bed nucleus of the stria terminalis); and 3) the superficial or cortex-like group, which is part of the caudal olfactory cortex (the anterior and posterior cortical nuclei, the nucleus of the olfactory tract, and periamygdaloid cortex). Furthermore, Price and others [14, 16, 19] included to the amygdalohippocampal areas, as well as groups of intercalated nuclei.

\section{EXTRA- AND INTRA-AMYGDALA INPUTS INTO MAJOR SUBNUCLEI OF THE AMYGDALA}

Based on the nomenclature used in the rat brain atlas of Paxinos and Watson [23], extra- and intra-amygdala inputs into major subnuclei including the central amygdaloid nucleus, medial amygdaloid nucleus, basal amygdaloid nucleus (basomedial amygdaloid nucleus and basolateral amygdaloid nucleus), lateral amygdaloid nucleus and cortical amygdaloid nucleus were investigated extensively by injection of $\mathrm{CTb}$ into each subnucleus, respectively. The sites of $\mathrm{CTb}$ injection into various amygdaloid subnuclei are shown in Table 1 
and Fig. 3. Table 1 shows detailed mapping of retrogradely labeled neurons following injection of $\mathrm{CTb}$ into various amygdaloid subnuclei.

\section{Central amygdaloid nucleus}

The central amygdaloid nucleus consists of capsular, lateral, intermediate and medial subdivisions. It is located at the dorsomedial part of the rostral half of the amygdala, and medial to the lateral and basal nuclei and lateral to the stria terminalis.

The distributions and the sites of the CTb injection into the central amygdaloid nucleus are shown in Fig. 3, 1-4 and in Table 1. In Case 1, the site of CTb injection was distributed in the medial division and the capsular part and the medial side of the lateral division between Bregma-1.60 mm and Bregma- $2.56 \mathrm{~mm}$. $\mathrm{CTb}$ was spread in the dorsal part of intraamygdaloid division of the bed nucleus of the stria terminalis at the level of Bregma-2.56 mm. In Case 2, the site of $\mathrm{CTb}$ injection was distributed in the medial division and the capsular part and the medial side of the lateral division between the Bregma-1.60 mm and Bregma-3.30 mm. $\mathrm{CTb}$ was spread in the dorsal part of intraamygdaloid division of the bed nucleus of the stria terminalis at the level of Bregma-3.14 mm. In Case 3, the site of $\mathrm{CTb}$ injection was distributed in the medial division and the lateral division between Bregma- $1.60 \mathrm{~mm}$ and Bregma-2.56 mm. In Case 4, the site of CTb injection was distributed in the medial division and the capsular part and the lateral division between Bregma-2.80 mm and Bregma- $3.30 \mathrm{~mm}$. CTb was spread in the dorsal part of intraamygdaloid division of the bed nucleus of the stria terminalis at the level of Bregma- $3.60 \mathrm{~mm}$.

The central amygdaloid nucleus received moderate to heavy inputs from almost all amygdaloid subnuclei. Inputs from the posterior part of the basolateral amygdaloid nucleus, anterior and posterior part of the basomedial amygdaloid nucleus and anterior cortical amygdaloid nucleus were the strongest, followed by the anterior amygdaloid area, medial amygdaloid nucleus, intercalated amygdaloid nucleus, posterolateral cortical amygdaloid nucleus and posteromedial cortical amygdaloid nucleus. The central amygdaloid nucleus received a light input from the contralateral amygdaloid subnuclei.

The central amygdaloid nucleus received extensively broad inputs from the cortex, hippocampal formation, thalamus, hypothalamus, basal forebrain, striatum, and bed nucleus of the stria terminalis, midbrain, pons and medulla.
The central amygdaloid nucleus received the most substantial projection from the amygdalopiriform transition area, followed by the amygdalohippocampal area and field CA1 of the hippocampus. In some cases, fields CA2 and CA3 of the hippocampus were also involved. Projection from the agranular insular cortex, especially from the posterior part was substantial. Projections from dorsal and ventral parts of the agranular insular cortex and dysgranular insular cortex were moderate. The central amygdaloid nucleus received a substantial input from the infralimbic cortex, and a light input from the prelimbic cortex. The central amygdaloid nucleus received light projections from various parts of the olfactory cortex including the dorsal peduncular cortex, dorsal and ventral endopiriform nuclei, perirhinal cortex and piriform cortex. In some cases, light inputs from the primary somatosensory cortex, secondary somatosensory cortex, medial orbital cortex, the lateral orbital cortex were observed.

The central amygdaloid nucleus received light inputs from the basal forebrain, striatum, and such as accumbens nucleus, and lateral septal nucleus. Projections from the bed nucleus of the stria terminalis and interstitial nucleus of the posterior limb of the anterior commissure were moderate. The central amygdaloid nucleus received light to moderate inputs from various nuclei in the hypothalamus and the thalamus. In the hypothalamus, projection from the ventromedial hypothalamic nucleus was substantial. Light projections were observed in some cases from the magnocellular preoptic nucleus, lateral preoptic area, medial preoptic area, paraventricular hypothalamic nucleus, anterior hypothalamic area, lateral hypothalamic area, retrochiasmatic area, dorsomedial hypothalamic nucleus, posterior hypothalamic area, premammillary nucleus, medial mammillary nucleus, supramammmilary nucleus and arcuate hypothamic nucleus. In the thalamus, projections from the paraventricular thalamic nucleus and medial geniculate nucleus were substantial. Moderate projections were observed from the paratenial thalamic nucleus and parvicellular part of the subparafascicular thalamic nucleus. In some cases, light projections were observed from the substantia innominata, central medial thalamic nucleus, mediodorsal thalamic nucleus, parasubthalamic nucleus, parafascicular thalamic nucleus, ethmoid thalamic nucleus, retroethmoid nucleus, posterior intralaminar thalamic nucleus and ventral posterolateral thalamic nucleus.

The central amygdaloid nucleus received light to moderate inputs from some nuclei in the midbrain and brain stem. Projections from the lateral and 


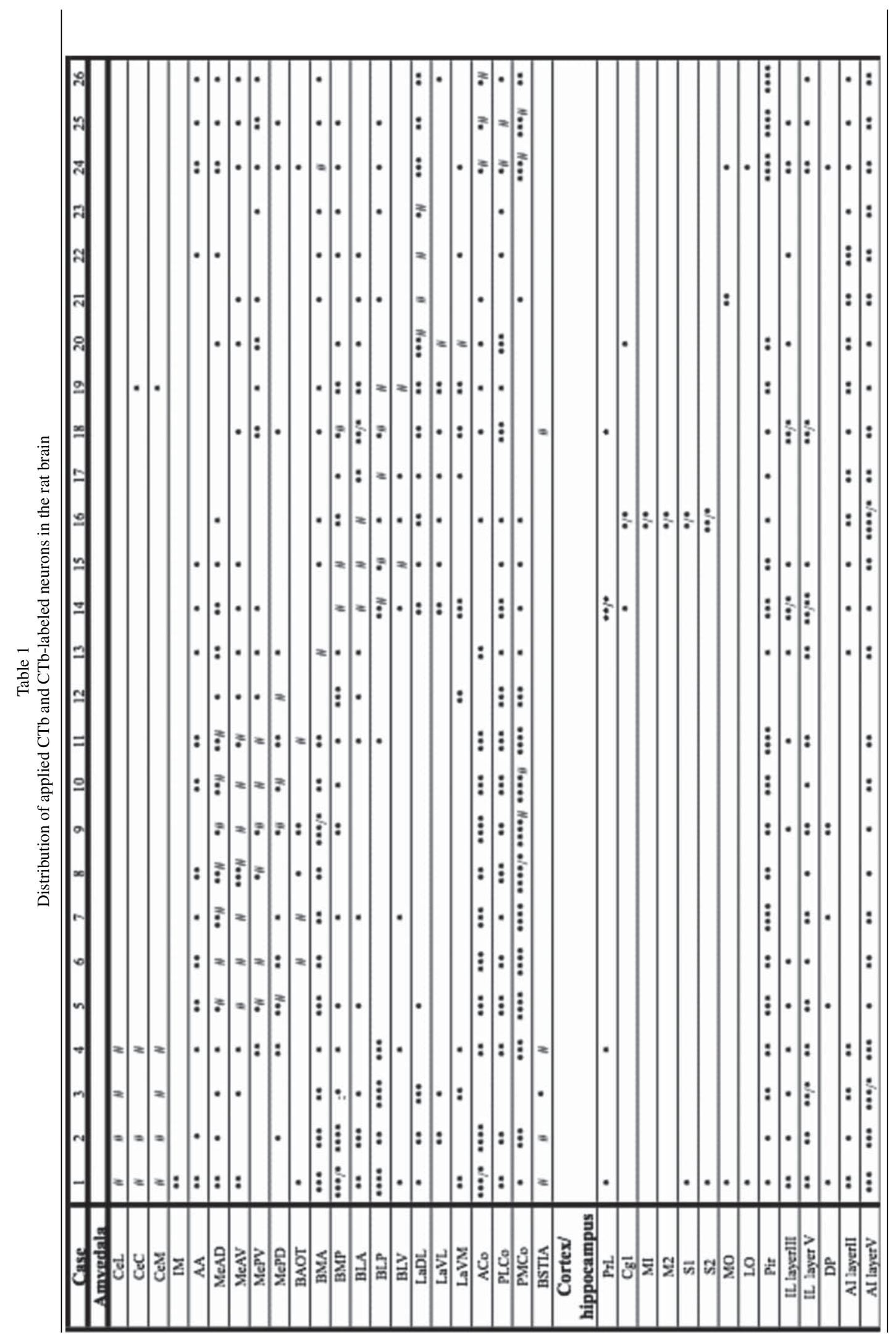




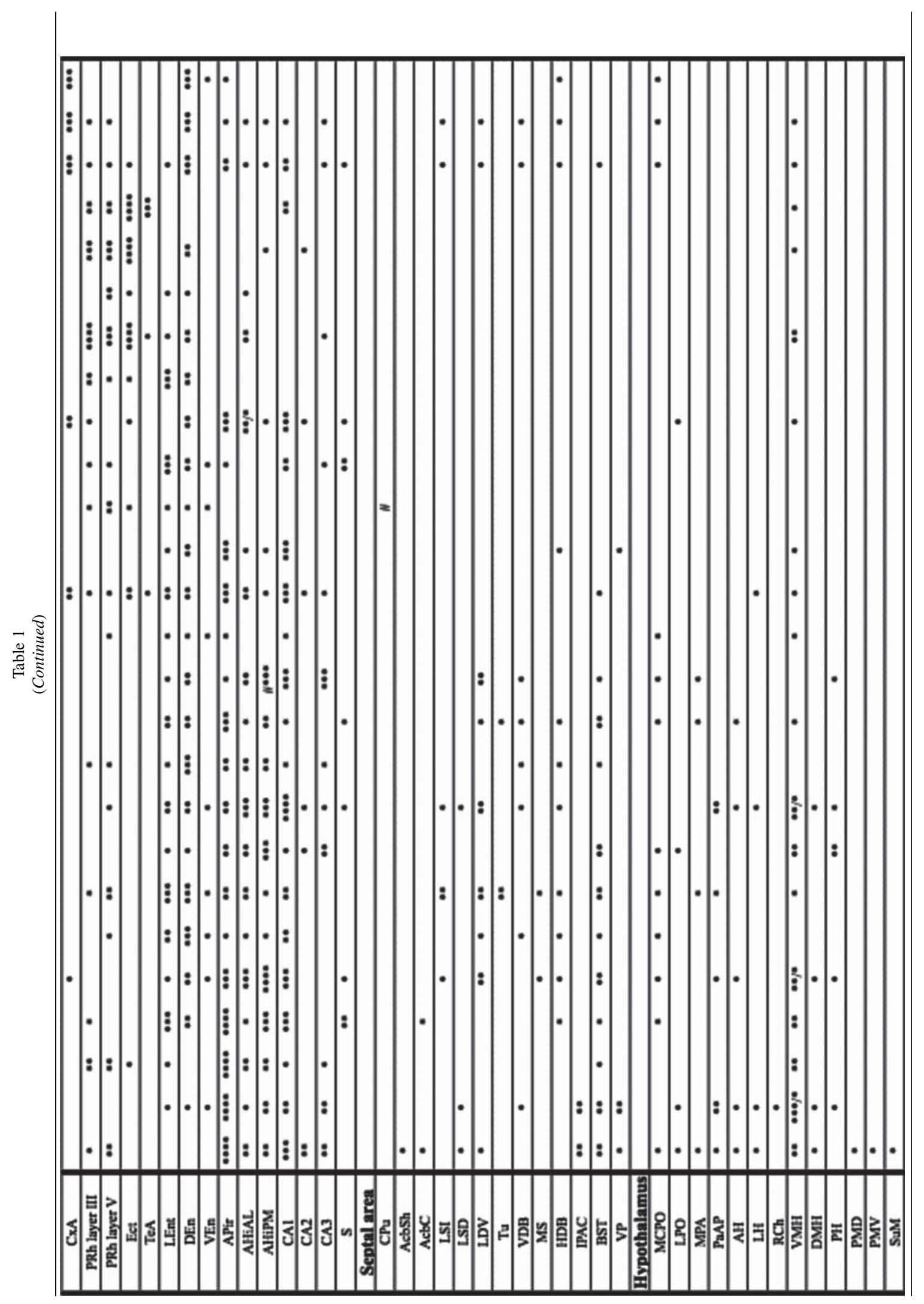




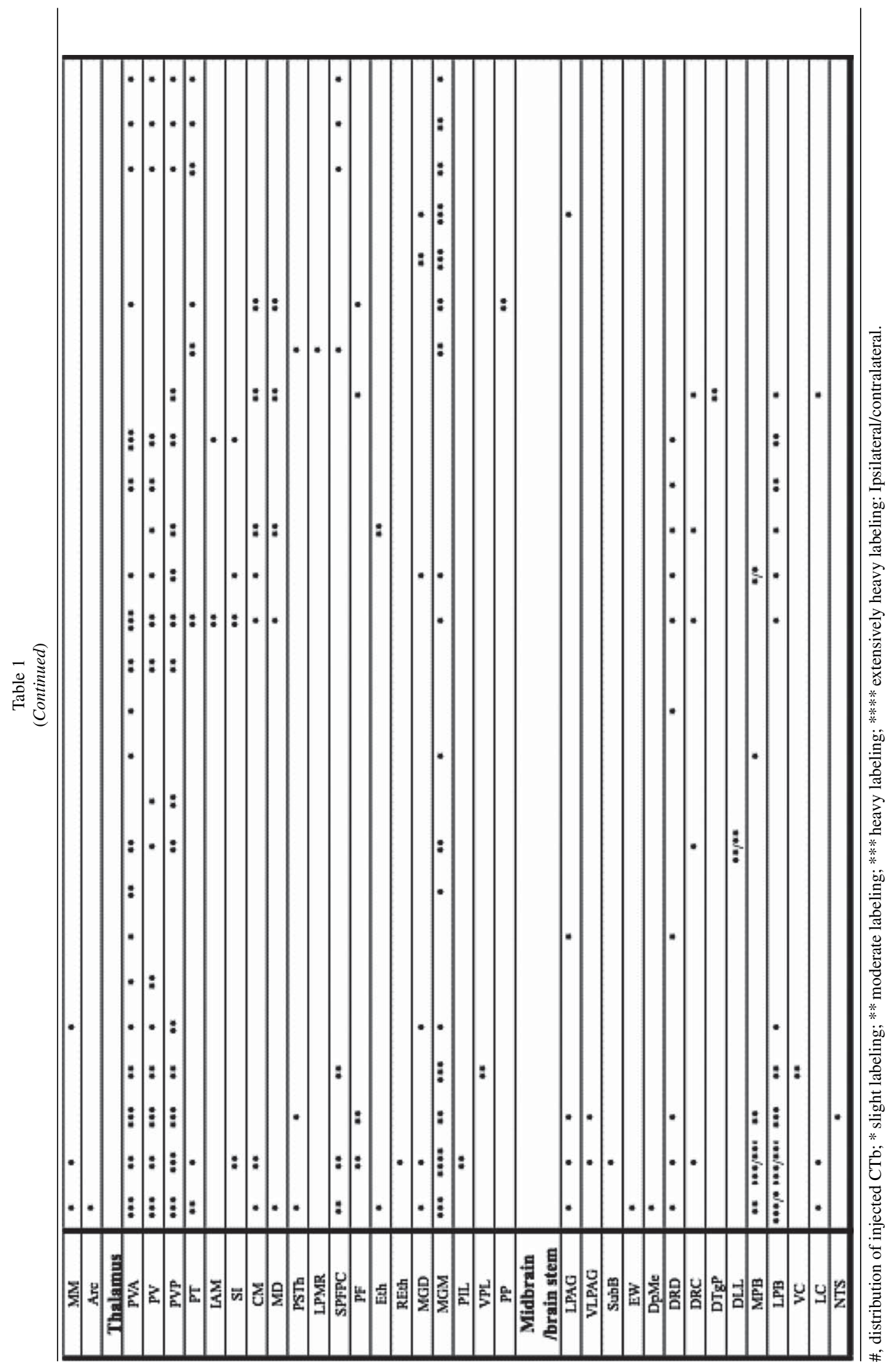




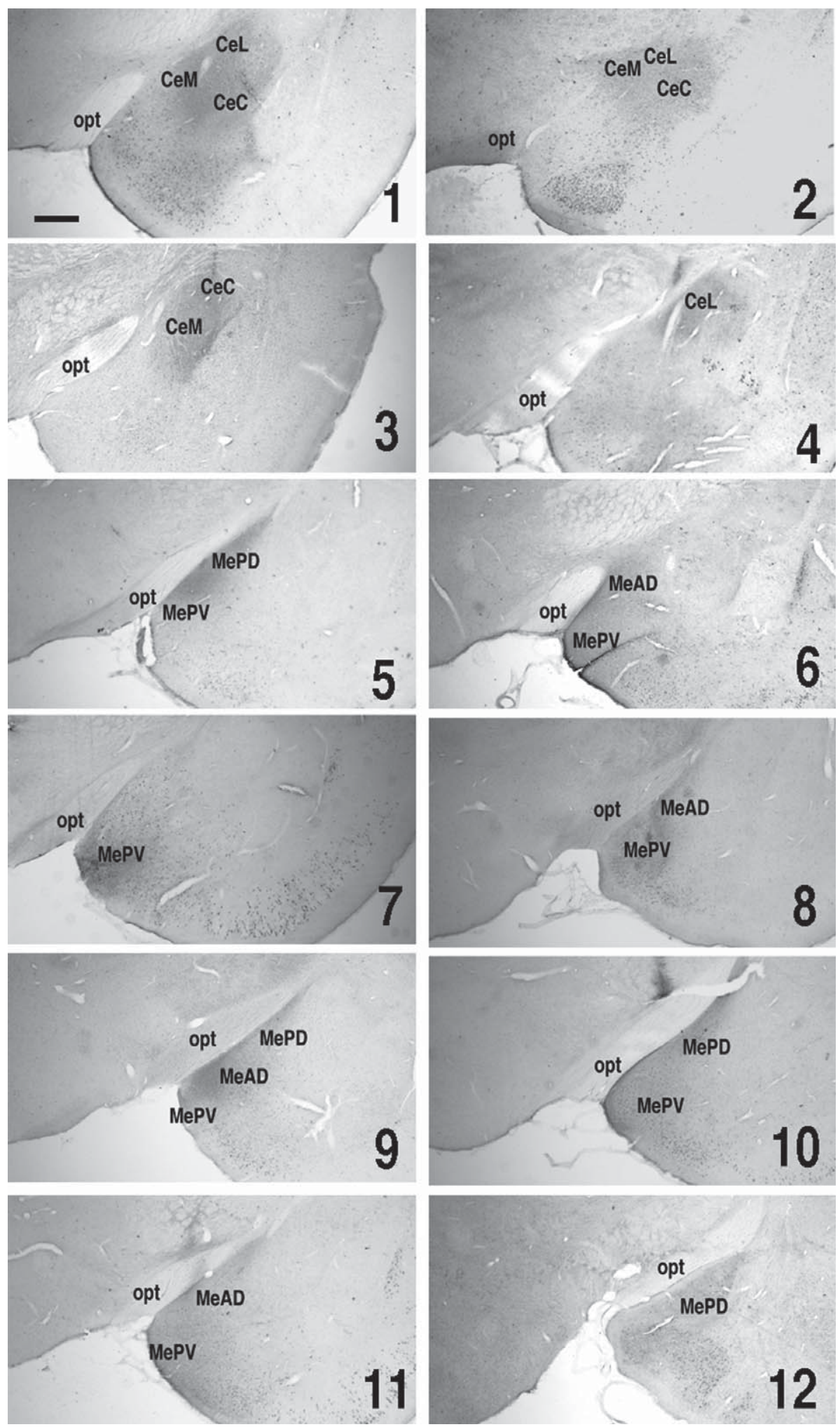

Fig. 3. The sites of $\mathrm{CTb}$ injection into various amygdaloid subnuclei. $\mathrm{CTb}$ was injected to the each amygdaloid subnucleus of adult female Wistar rats based on coordinates from a rat brain atlas [23]. The brains were fixed after 7 days, followed by immunohistochemical detection of $\mathrm{CTb}$. 

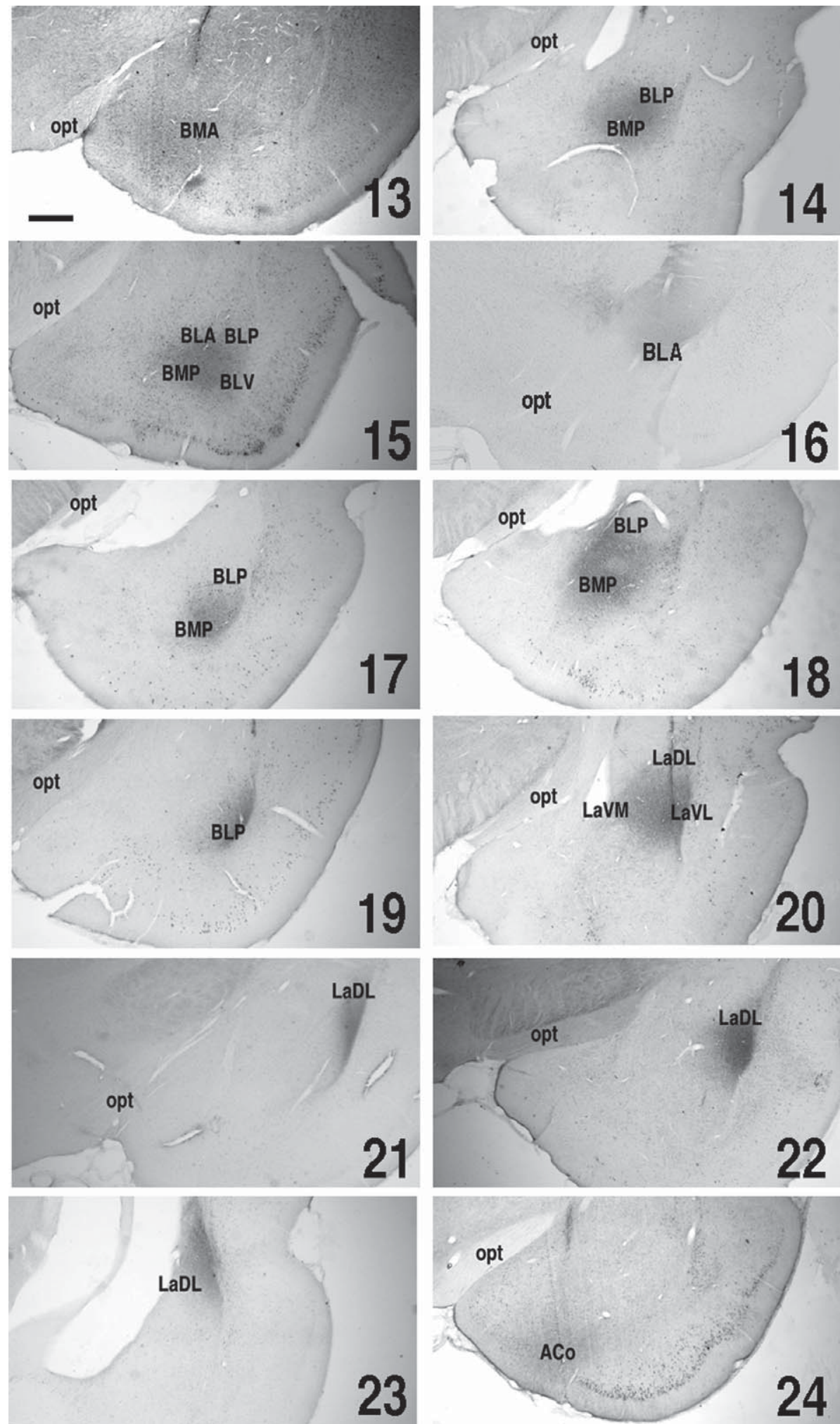

Fig. 3. (Continued) 

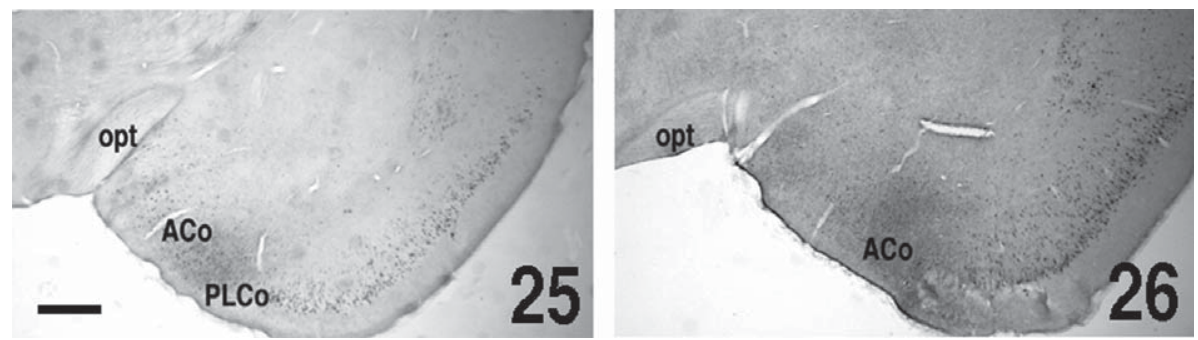

Fig. 3. (Continued)

medial parabrachial nucleus were substantial. Light projection was observed from the lateral periaqueductal gray, ventrolateral periaqueductal gray and dorsal raphe nucleus. In some cases, light projections were observed from the subbrachial nucleus, EdingerWestphal nucleus, locus coeruleus and nucleus of the solitary tract.

In summary, the central amygdaloid nucleus received moderate to heavy inputs from almost all amygdaloid subnuclei, and from the limbic cortex and hippocampus (amygdalopiriform transition area and agranular insular cortex), thalamus (paraventricular thalamic nucleus, medial geniculate nucleus), hypothalamus (ventromedial hypothalamic nucleus) and midbrain (parabrachial nucleus).

\section{Medial amygdaloid nucleus}

The medial amygdaloid nucleus consists of anteroventral, anterodorsal, posteroventral and posterodorsal subdivisions. The medial amygdaloid nucleus begins at the level of the nucleus of the lateral olfactory tract and extends caudally to where the lateral ventricle begins.

The distributions and the sites of the CTb injection into the medial amygdaloid nucleus are shown in Fig. 3, 5-12 and in Table 1. In Case 5, the site of $\mathrm{CTb}$ injection was distributed in the medial side of the anterodorsal part, anteroventral part, posterodorsal part and posteroventral part of the medial amygdaloid nucleus between Bregma-2.12 mm and Bregma-3.30 mm. In Case 6, the site of CTb injection was distributed in the medial side of the anterodorsal part, anteroventral part and posteroventral part of the medial amygdaloid nucleus between Bregma$1.88 \mathrm{~mm}$ and Bregma-3.30 mm. CTb was spread in the bed nucleus of the accessory olfactory tract at the level of Bregma-1.88 mm. In Case 7, the site of $\mathrm{CTb}$ injection was distributed in the medial side of the anteroventral part and anterodorsal part of the medial amygdaloid nucleus between Bregma- $1.40 \mathrm{~mm}$ and
Bregma- $2.80 \mathrm{~mm}$. CTb was spread in the bed nucleus of the accessory olfactory tract at the level of Bregma$2.12 \mathrm{~mm}$. In Case 8, the site of CTb injection was distributed in the medial side of the anterodorsal part, anteroventral part and posteroventral part of the medial amygdaloid nucleus between the Bregma-2.12 $\mathrm{mm}$ and Bregma-3.14 mm. In Case 9, the site of CTb injection was distributed in the anterodorsal part, anteroventral part, posterodorsal and posteroventral part of the medial amygdaloid nucleus between Bregma- $2.30 \mathrm{~mm}$ and Bregma-3.14 mm. In Case 10, the site of CTb injection was distributed in the medial side of anterodorsal part, anteroventral part, posterodorsal part and posteroventral part of the medial amygdaloid nucleus between Bregma-2.12 mm and Bregma-3.60 mm. CTb was spread in the posteromedial cortical amygdaloid nucleus at the level of Bregma-3.60 mm. In Case 11, the site of CTb injection was distributed in the anteroventral part, anterodorsal part, and posteroventral part of the medial amygdaloid nucleus between Bregma$2.30 \mathrm{~mm}$ and Bregma-3.30 mm. CTb was spread in the bed nucleus of the accessory olfactory tract at the level of Bregma-2.30 mm. In Case 12, the site of CTb injection was distributed in the posteroventral part of the medial amygdaloid nucleus between Bregma-3.14 mm and Bregma- $3.60 \mathrm{~mm}$.

The medial amygdaloid nucleus received moderate to heavy inputs from the basomedial and cortical amygdaloid nuclei. Input from the posteromedial cortical amygdaloid nucleus was the strongest, followed by the posterolateral cortical amygdaloid nucleus and anterior cortical amygdaloid nucleus. Moderate input was observed from the anterior amygdaloid area.

The medial amygdaloid nucleus received substantial broad inputs from the cortex, hippocampal formation, thalamus, hypothalamus, basal forebrain, striatum, and bed nucleus of the stria terminalis. The medial amygdaloid nucleus received most substantial projections from the amygdalohippocampal area, field CA1 of the hippocampus, amygdalopiriform transition area and piriform cortex. Projections from the infralimbic 
cortex, agranular insular cortex, dorsal endopiriform nucleus and lateral entorhinal cortex were moderate. In some cases, the perirhinal cortex and fields CA2 and CA3 of the hippocampus were also involved.

The medial amygdaloid nucleus received light inputs from the basal forebrain, striatum, lateral septal nucleus, nucleus of the horizontal limb of the diagonal band and bed nucleus of the stria terminalis. The medial amygdaloid nucleus received light to moderate inputs from various nuclei in the hypothalamus and the thalamus. In some cases, projection from the ventromedial hypothalamic nucleus was moderate. Light projection was observed in some cases from other hypothalamic nuclei. In the thalamus, projection from the paraventricular thalamic nucleus was moderate. In some cases, a light projection was observed from the medial geniculate nucleus.

In summary, the medial amygdaloid nucleus received moderate to heavy inputs from the basomedial amygdaloid nucleus, cortical amygdaloid nucleus, limbic cortex and hippocampus (piriform cortex, amygdalohippocampal area, field CA1 of the hippocampus), thalamus (paraventricular thalamic nucleus) and hypothalamus (ventromedial hypothalamic nucleus).

\section{Basal amygdaloid nucleus}

The basal amygdaloid nucleus is divided into lateral and medial parts. The lateral part is defined as the basal nucleus, and the medial part is defined as the accessory basal nucleus [19]. The basal amygdaloid nucleus consists of the anterior, posterior and ventral part of basolateral amygdaloid nucleus, the anterior part and posterior part of basomedial amygdaloid nucleus. The basal amygdaloid nucleus is located ventral to the central amygdaloid nucleus and the lateral amygdaloid nucleus, lateral to the nucleus of the lateral olfactory tract and the medial amygdaloid nucleus, dorsal to the cortical amygdaloid nucleus and medial to the ventral endopiriform nucleus.

The distributions and the sites of the CTb injection into the basal amygdaloid nucleus are shown in Fig. 3, 13-19 and in Table 1. In Case 13, the site of $\mathrm{CTb}$ injection was distributed in the anterior part of the basomedial amygdaloid nucleus between Bregma$2.12 \mathrm{~mm}$ and Bregma-2.56 mm. In Case 14, the site of $\mathrm{CTb}$ injection was distributed in the posterior part of the basomedial amygdaloid nucleus, the anterior and posterior part of the basolateral amygdaloid nucleus between Bregma-3.14 mm and Bregma- $4.30 \mathrm{~mm}$. In Case 15, the site of CTb injection was distributed in the posterior part of the basomedial amygdaloid nucleus, and the anterior, ventral and posterior part of the basolateral amygdaloid nucleus between Bregma-3.14 mm and $-3.60 \mathrm{~mm}$. In Case 16, the site of CTb injection was distributed in the anterior part of the basolateral amygdaloid nucleus between Bregma- $1.60 \mathrm{~mm}$ and Bregma- $2.30 \mathrm{~mm}$. CTb was spread in the ventral part of the caudate putamen between Bregma- $1.60 \mathrm{~mm}$ and Bregma- $2.30 \mathrm{~mm}$. In Case 17, the site of CTb injection was distributed in the posterior part of the basolateral amygdaloid nucleus between Bregma- $3.60 \mathrm{~mm}$ and Bregma-4.80 mm. In Case 18, the site of CTb injection was distributed in the anterior and posterior parts of the basomedial amygdaloid nucleus and the posterior part of the basolateral amygdaloid nucleus between Bregma-3.14 mm and $3.80 \mathrm{~mm}$. CTb was spread in the intraamygdaloid division of the bed nucleus of the stria terminalis between Bregma-3.14 mm and Bregma$3.60 \mathrm{~mm}$. In Case 19, the site of CTb injection was distributed in the posterior and ventral parts of the basolateral amygdaloid nucleus between Bregma-3.14 mm and Bregma- $4.16 \mathrm{~mm}$.

The basomedial amygdaloid nucleus received light to moderate inputs from the anterior amygdaloid area, medial amygdaloid nucleus, cortical amygdaloid nucleus and basolateral amygdaloid nucleus. The basomedial amygdaloid nucleus received light to moderate inputs from the cortex, hippocampal formation, thalamus and hypothalamus. The basomedial amygdaloid nucleus received moderate projection from the agranular insular cortex and paraventricular thalamic nucleus. Projections from the piriform cortex, infralimbic cortex, lateral entorhinal cortex, dorsal endopiriform nucleus, amygdalopiriform transition area, field CA1 of the hippocampus, magnocellular preoptic nucleus and ventromedial hypothalamic nucleus were small.

The basolateral amygdaloid nucleus received light to heavy inputs from the medial amygdaloid nucleus, basomedial amygdaloid nucleus, lateral amygdaloid nucleus and cortical amygdaloid nucleus. Inputs from the lateral amygdaloid nucleus were the strongest, followed by the posterlateral cortical amygdaloid nucleus. In some cases, light projections from the anterior amygdaloid area, medial amygdaloid nucleus, central amygdaloid nucleus, and anterior and posteromedial cortical amygdaloid nuclei were observed.

The basolateral amygdaloid nucleus received light to heavy inputs from the cortex, hippocampal formation, thalamus, hypothalamus, midbrain and brain stem. The basolateral amygdaloid nucleus received substantial projections from the agranular insular cortex, amygdalopiriform transition area, field 
CA1 of the hippocampus and posteromedial part of the amygdalohippocampal area. Projections from the piriform cortex, lateral entorhinal cortex, dorsal endopiriform nucleus and anterolateral part of amygdalohippocampal area were moderate. In some cases, the cortex-amygdala transition zone, perirhinal cortex, and ectorhinal cortex were also involved. Light inputs from the cingulate cortex, primary motor cortex, secondary motor cortex, primary somatosensory cortex, and secondary somatosensory cortex were observed when $\mathrm{CTb}$ was distributed in the caudate putamen (Case 16).

The basolateral amygdaloid nucleus received substantial projections from the paraventricular thalamic nucleus. In some cases, other thalamic nuclei such as the paratenial thalamic nucleus, interanteromedial thalamic nucleus, central medial thalamic nucleus, mediodorsal thalamic nucleus, parasubthalamic nucleus, parafascicular thalamic nucleus, ethmoid thalamic nucleus, medial geniculate nucleus and substantia innominata were involved. In some cases, light projections from the hypothalamic nuclei such as the ventromedial hypothalamic nucleus, magnocellular preoptic nucleus and lateral hypothalamic area were observed. The basolateral amygdaloid nucleus also received light projections from midbrain structures, such as the dorsal raphe nucleus and parabrachial nucleus.

In summary, the basomedial amygdaloid nucleus received moderate inputs from the medial amygdaloid nucleus, cortical amygdaloid nucleus and basolateral amygdaloid nucleus, and from limbic cortex and hippocampus (agranular insular cortex) and thalamus (paraventricular thalamic nucleus). The basolateral amygdaloid nucleus received moderate inputs from the lateral amygdaloid nucleus, medial amygdaloid nucleus, basomedial amygdaloid nucleus and cortical amygdaloid nucleus, and from limbic cortex and hippocampus (lateral entorhinal cortex, amygdalopiriform transition area, field CA1 of the hippocampus), thalamus (paraventricular thalamic nucleus) and midbrain (parabrachial nucleus).

\section{Lateral amygdaloid nucleus}

The lateral amygdaloid nucleus is located at the dorsal part of the amygdala, medial to the external capsule and lateral to both to the central amygdaloid nucleus (rostrally) and the lateral ventricle (caudally), and ventral to the basal amygdaloid nucleus. The lateral amygdaloid nucleus has three divisions:dorsolateral, ventrolateral and ventromedial.
The distributions and the sites of the $\mathrm{CTb}$ injection into the lateral amygdaloid nucleus are shown in Fig. 3, 20-23 and in Table 1. In Case 20, the site of $\mathrm{CTb}$ injection was distributed in the dorsolateral, ventromedial and ventrolateral parts of the lateral amygdaloid nucleus between Bregma- $2.30 \mathrm{~mm}$ and Bregma- $4.16 \mathrm{~mm}$. In Case 21, the site of CTb injection was distributed in the dorsolateral part of the lateral amygdaloid nucleus between Bregma- $1.88 \mathrm{~mm}$ and Bregma-3.14 mm. In Case 22, the site of CTb injection was distributed in the dorsolateral part of the lateral amygdaloid nucleus between Bregma- $2.56 \mathrm{~mm}$ and Bregma-3.14 mm. In Case 23, the site of CTb injection was distributed in the dorsolateral part of the lateral amygdaloid nucleus between Bregma- $3.30 \mathrm{~mm}$ and Bregma-4.16 $\mathrm{mm}$.

The lateral amygdaloid nucleus received light to moderate inputs from the medial amygdaloid nucleus, cortical amygdaloid nucleus, basomedial amygdaloid nucleus and basolateral amygdaloid nucleus. The lateral amygdaloid nucleus received the most substantial projections from the ectorhinal cortex and perirhinal cortex, followed by the agranular insular cortex and dorsal endopiriform nucleus and lateral entorhinal cortex. Light to moderate projections from the piriform cortex, infralimbic cortex and amygdalohippocampal area were observed. Inputs from the hypothalamus, thalamus, midbrain and pons were limited. The lateral amygdaloid nucleus received strong projection from the medial geniculate nucleus and light projection from the ventromedial hypothalamic nucleus. In some cases, light projections from the paraventricular thalamic nucleus, paratenial thalamic nucleus, central medial thalamic nucleus, mediodorsal thalamic nucleus and ventral posterolateral thalamic nucleus and peripeduncular nucleus were observed.

In summary, the lateral amygdaloid nucleus received moderate to heavy inputs from the medial amygdaloid nucleus, cortical nucleus, basomedial amygdaloid nucleus and basolateral amygdaloid nucleus, and from limbic cortex (ectorhinal cortex, perirhinal cortex), thalamus (medial geniculate nucleus) and hypothalamus (ventromedial hypothalamic nucleus).

\section{Cortical amygdaloid nucleus}

The cortical amygdaloid nucleus has three divisions: anterior, posteromedial and posterolateral. The anterior cortical amygdaloid nucleus is located ventral to the anterior part of the basomedial amygdaloid nucleus. Laterally, it is bordered rostrally by the cortex-amygdala transition zone, and caudally by the 
posterolateral cortical amygdaloid nucleus. Rostromedially, it is bordered by the nucleus of the lateral olfactory tract, and caudomedially by the medial amygdaloid nucleus. The posterolateral cortical amygdaloid nucleus is called the periamygdaloid cortex [19]. The posterolateral cortical amygdaloid nucleus is located ventral to the anterior part of the basomedial amygdaloid nucleus. Laterally, it is bordered rostrally by the cortex-amygdala transition zone, and caudally by the piriform cortex. Rostromedially, it is bordered by the anterior cortical amygdaloid nucleus, and, caudomedially, by the posteromedial cortical amygdaloid nucleus. The posteromedial cortical amygdaloid nucleus forms the most caudal part of the amygdaloid complex. It is bordered dorsally by the amygdalohippocampal area, and laterally by the amygdalopiriform transition area.

The distributions and the sites of the CTb injection into the cortical amygdaloid nucleus are shown in Fig. 3, 24-26 and in Table 1. In Case 24, the site of $\mathrm{CTb}$ injection was distributed in the anterior cortical amygdaloid nucleus and posterolateral cortical amygdaloid nucleus between Bregma-2.12 mm and Bregma-3.80 mm. CTb was spread in the anterior part of the basomedial amygdaloid nucleus and in the lateral side of the posteromedial cortical amygdaloid nucleus. In Case 25, the site of CTb injection was distributed in the anterior cortical amygdaloid nucleus, posterolateral cortical amygdaloid nucleus and posteromedial cortical amygdaloid nucleus between Bregma-2.12 mm and Bregma-3.80 mm. In Case 26, the site of $\mathrm{CTb}$ injection was distributed in the anterior cortical amygdaloid nucleus between Bregma$1.60 \mathrm{~mm}$ and Bregma- $2.12 \mathrm{~mm}$.

The cortical amygdaloid nucleus received light to heavy inputs from the medial amygdaloid nucleus, basomedial amygdaloid nucleus and basolateral amygdaloid nucleus and lateral amygdaloid nucleus. Inputs from the dorsolateral part of the lateral amygdaloid nucleus are the strongest, followed by the medial amygdaloid nucleus.

The cortical amygdaloid nucleus received inputs from the cortex, hippocampal formation, thalamus and hypothalamus. The cortical amygdaloid nucleus received the most substantial projection from the piriform cortex, followed by the cortex-amygdala transition zone and dorsal endopiriform nucleus and agranular insular cortex. Light to moderate projections were observed from the infralimbic cortex, lateral entorhinal cortex, amygdalopiriform transition area, amygdalohippocampal area and field CA1 of the hippocampus. The cortical amygdaloid nucleus received light to moderate projections from the paratenial tha- lamic nucleus, paraventricular thalamic nucleus and medial part of medial geniculate nucleus. Light projections were observed from the lateral septal nucleus, nucleus of the horizontal limb of the diagonal band, nucleus of the vertical limb of the diagonal band, bed nucleus of the stria terminalis, magnocellular preoptic nucleus, ventromedial hypothalamic nucleus, and subparafascicular thalamic nucleus.

In summary, the cortical amygdaloid nucleus received light to heavy inputs from the lateral amygdaloid nucleus, medial amygdaloid nucleus, and from limbic cortex and hippocampus (piriform cortex, dorsal endopiriform nucleus and agranular insular cortex) and thalamus (paraventricular thalamic nucleus, paratenial thalamic nucleus and medial geniculate nucleus).

\section{Summary of the afferent projection and intra-amygdaloid connection}

Afferent projections to each subnuclei and mutual connections among subnuclei are summarized in Fig. 4. All amygdaloid subnuclei receive psychological information from other limbic brain regions, while the lateral amygdaloid nucleus and central amygdaloid nucleus receive peripheral and sensory information via the parabrachial nucleus and medial geniculate nucleus. The central amygdaloid nucleus receives afferent projection from all the other amygdaloid subnuclei. These anatomical observations support the differences of stressor organization. Physical stress such as hemorrhage and immune challenge elicited c-Fos expression in the central amygdaloid nucleus, whereas psychological stress such as noise, restraint and forced swim primarily elicited c-Fos expression in the medial amygdaloid nucleus [7, 22, 24, 25].

\section{EFFERENT PROJECTIONS FROM THE MEDIAL AMYGDALOID NUCLEUS AND FROM THE CENTRAL AMYGDALOID NUCLEUS}

Efferent projections from the medial amygdaloid nucleus were demonstrated using anterograde neuronal tracing with PHAL $[26,27]$. The most dense outputs from the medial amygdaloid nucleus are to the rest of the amygdaloid subnuclei, bed nucleus of the stria terminalis, and the hypothalamus. The medial amygdaloid nucleus is separated into ventral and dorsal divisions, and the ventral divisions are further separated into rostral and caudal regions. Canteras et al. [26] has reported in rats that the ventral division 

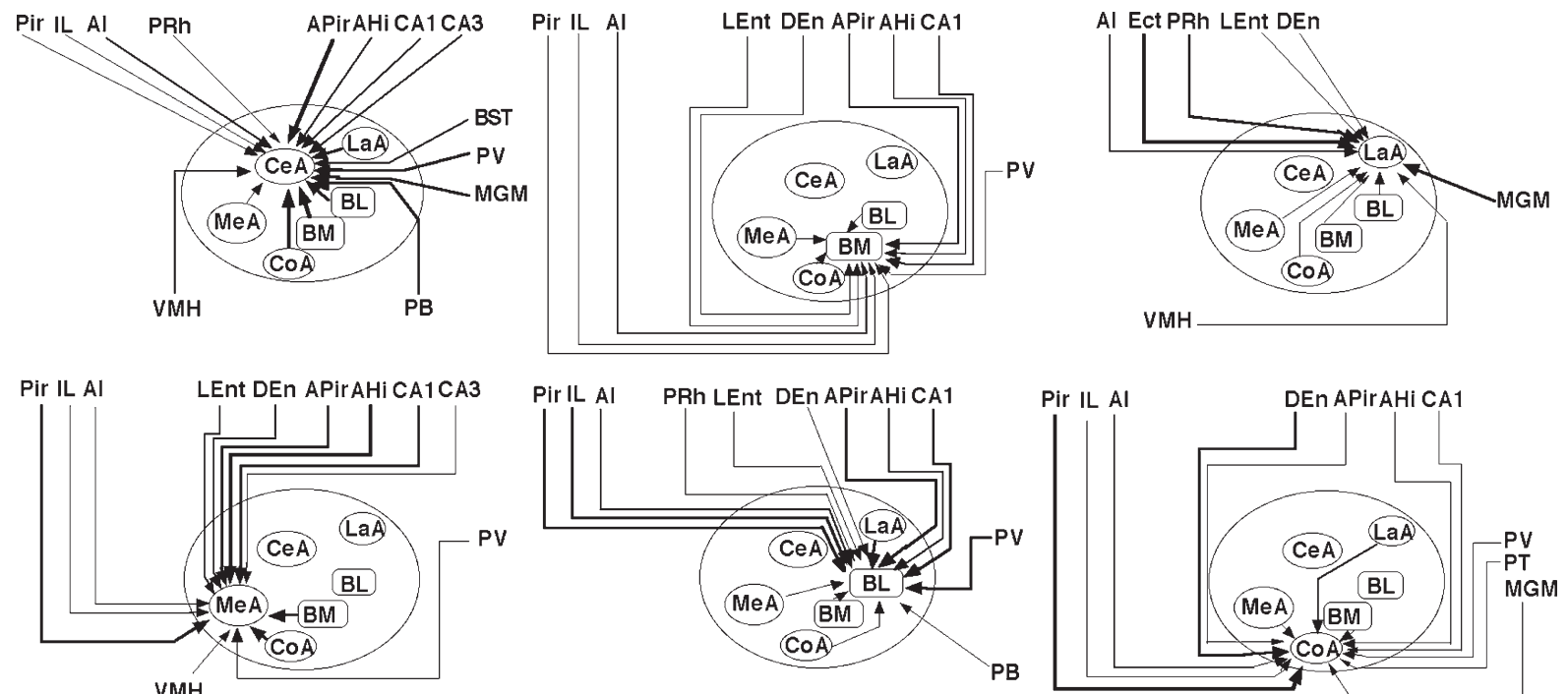

Fig. 4. Afferent projections to each subnucleus and cross-connections among intra-subnuclei. The width of the lines indicates the strength of connection. (This figure was reprinted from reference 44 with permission).

(the anterodorsal, anteroventral, and posteroventral medial amygdaloid nucleus) shows dense projection to the transverse and interfascicular nuclei of the bed nucleus of the stria terminalis, while the dorsal division (the posterodorsal medial amygdaloid nucleus) shows dense projection to the principal nucleus of bed nucleus of the stria terminalis. The ventral division projects intensively to the lateral part of the medial preoptic, anterior hypothalamic and ventromedial hypothalamic nuclei, while the dorsal division projects to the anteroventral periventricular, medial, and central parts of the medial preoptic, and ventral premammilary hypothalamic nuclei. In the intraamygdaloid connection, the ventral division (anterodorsal medial amygdaloid nucleus) shows dense inputs to the anterior amygdaloid area, bed nucleus of the accessory olfactory tract, central nucleus, anterior cortical nucleus, and deep layers of the piriform-amygdaloid area. The posteroventral medial amygdaloid nucleus projects to the anterior amygdaloid area, bed nucleus of the accessory olfactory tract, anterior and posterior parts of the basomedial nucleus, piriform-amygdaloid area, anterior and posterior cortical nuclei, and posterior nucleus. Unlike other parts of the medial amygdaloid nucleus, the posterodorsal divison shows dense projection to the posterior cortical nucleus and few projections to the anterior amygdaloid area, bed nucleus of the accessory olfactory tract, anterior and posterior basomedial nucleus, deep layers of the posterior cortical nucleus, and piriform-amygdaloid area.
Efferent projection from the amygdala to each hypothalamic nucleus was investigated by injecting retrograde neuronal tracer $\mathrm{CTb}$ in each hypothalamic nucleus (Fig. 5). The medial amygdaloid nucleus, especially the ventral parts were heavily labeled following injection of $\mathrm{CTb}$ in the anterior hypothalamic area (Fig. 5A), the medial preoptic nucleus (Fig. 5B), paraventricular hypothalamic nucleus, dorsomedial hypothalamic nucleus (Fig. 5C), ventromedial hypothalamic nucleus (Fig. 5D), periventricular hypothalamic nucleus, perifornical nucleus, lateral hypothalamic area, arcuate nucleus, suprachiasmatic nucleus and posterior hypothalamic area. These results suggest that the ventromedial part of the medial amygdaloid nucleus is the output region to the hypothalamus.

In contrast, direct projection from the central amygdaloid nucleus to the hypothalamus is limited. The bed nucleus of the stria terminalis receives extensive projections from the central amygdaloid nucleus $[28,29]$. The ventrolateral bed nucleus of the stria terminalis receives extensive inputs from the central amygdaloid nucleus and basomedial amygdaloid nucleus, and moderate input from the parabrachial nucleus and nucleus of the solitary tract [30]. Output projections from the ventrolateral bed nucleus of the stria terminalis target the dorsal part of the substantia innominata, hypothalamic nuclei such as the paraventricular hypothalamic nucleus, dorsomedial hypothalamic nucleus, perifornical nucleus and lateral hypothalamic area, central amygdaloid nucleus, peri- 

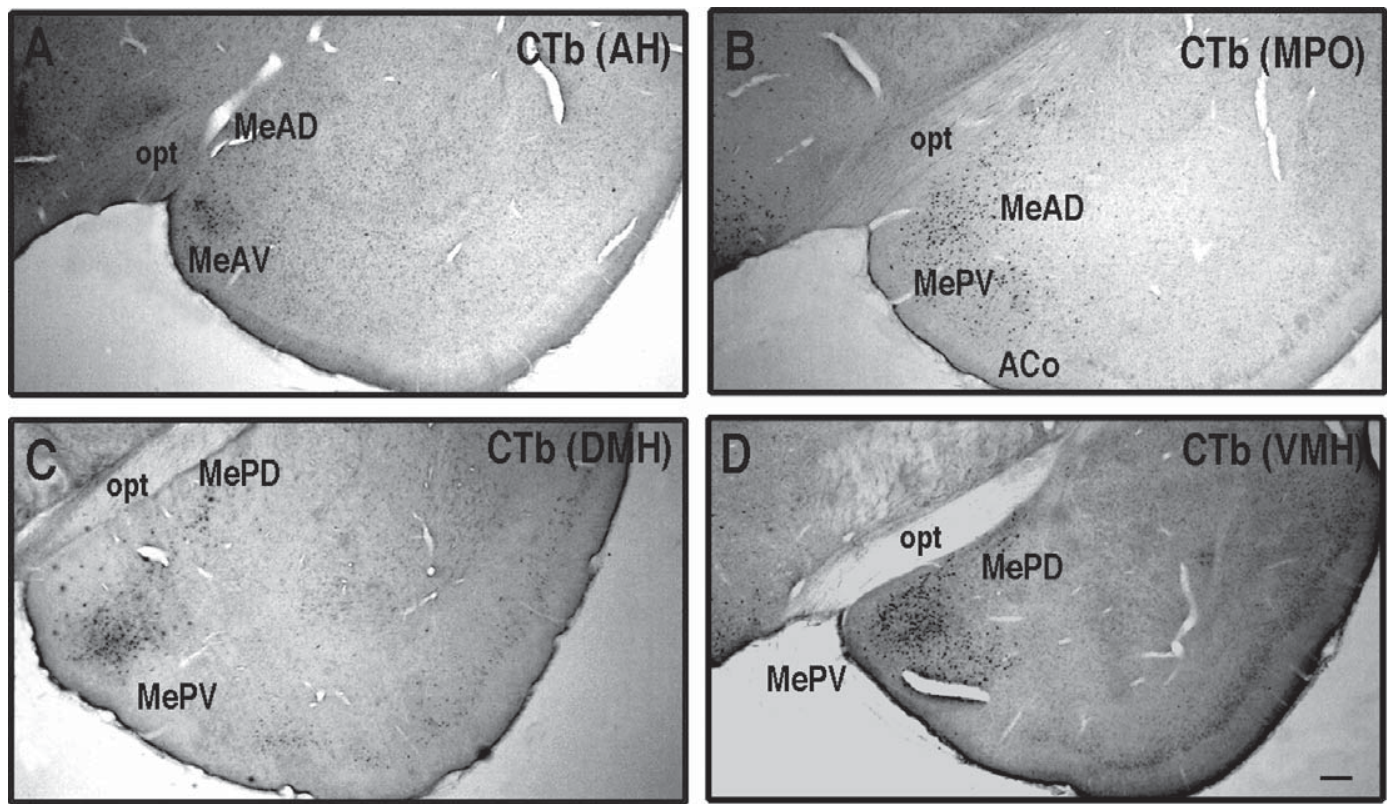

Fig. 5. Efferent projection to the hypothalamic nuclei from the medial amygdaloid nucleus. CTb was injected to each hypothalamic nucleus of adult female Wistar rats based on coordinates from a rat brain atlas [23]. The brains were fixed after 7 days, followed by immunohistochemical detection of CTb. (A) anterior hypothalmus area (AH). (B) medial preoptic nucleus (MPO). (C) dorsomedial hypothalamic nucleus (DMH). (D)

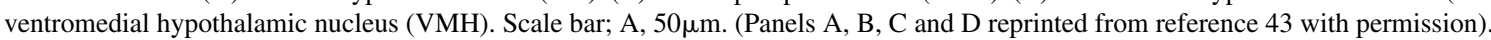

aqueductal gray, locus coeruleus, parabrachial nucleus and nucleus of the solitary tract, which are involved in autonomic nervous activity [31].

Bilateral central amygdaloid nucleus lesions significantly reduced IL-1 $\beta$-induced c-Fos expression in cells of the ventromedial and ventrolateral subdivisions of bed nucleus of the stria terminalis and brainstem catecholamine cell groups of the nucleus of the solitary tract (A2 noradrenergic cells) and ventrolateral medulla (A1 noradrenergic and $\mathrm{C} 1$ adrenergic cells) [32]. The parabrachial nucleus plays a critical role in IL-1 $\beta$-induced c-Fos expression in the central amygdaloid nucleus, bed nucleus of the stria terminalis and ventrolateral medulla neurons [25]. These observations suggest that immunological stress activates the pathway that includes the parabrachial nucleus, central amygdaloid nucleus, and ventromedial and ventrolateral subdivisions of the bed nucleus of the stria terminalis.

\section{INVOLVEMENT OF SEX STEROID IN THE MEDIAL AMYGDALOID NUCLEUS}

Since estrogen receptors (ER $\alpha$ and $E R \beta)$ and androgen receptor (AR) are widely expressed in the cardiovascular system [33] and in the central ner- vous system [34-36], estrogen and androgen have various functions such as the prevention of cardiovascular diseases, modulation of sexual behavior, memory processes and autonomic nervous function [37]. Reduction of estrogen levels following menopause or ovariectomy results in vulnerability to stress while estrogen supplement attenuates the exaggerated response to stress or sympathoadrenal activity [38, 39].

Within the amygdala, neurons in the medial amygdaloid nucleus express $\mathrm{ER} \alpha, \mathrm{ER} \beta$ and AR extensively [34-36]. The neurons in the medial amygdaloid nucleus projecting to the PVH express ER $\alpha$ (Fig. 6A), and are reactive to stress (Fig. 6B). Following estrogen treatment, the numbers of c-Fos IR neurons in response to IMO reduced in the lateral septal nucleus, paraventricular hypothalamic nucleus, dorsomedial hypothalamic nucleus, medial amygdaloid nucleus, and locus coeruleus [9]. Reduction of c-Fos IR by supplemental estrogen treatment in response to other stress protocols such as swimming stress or restriction stress has been demonstrated [40, 41]. In accordance with reduced expression of c-Fos IR, ER $\alpha$ and/or ER $\beta$ were expressed in the lateral septal nucleus, paraventricular hypothalamic nucleus, locus coeruleus and especially in the medial amygdaloid nucleus. These results sug- 

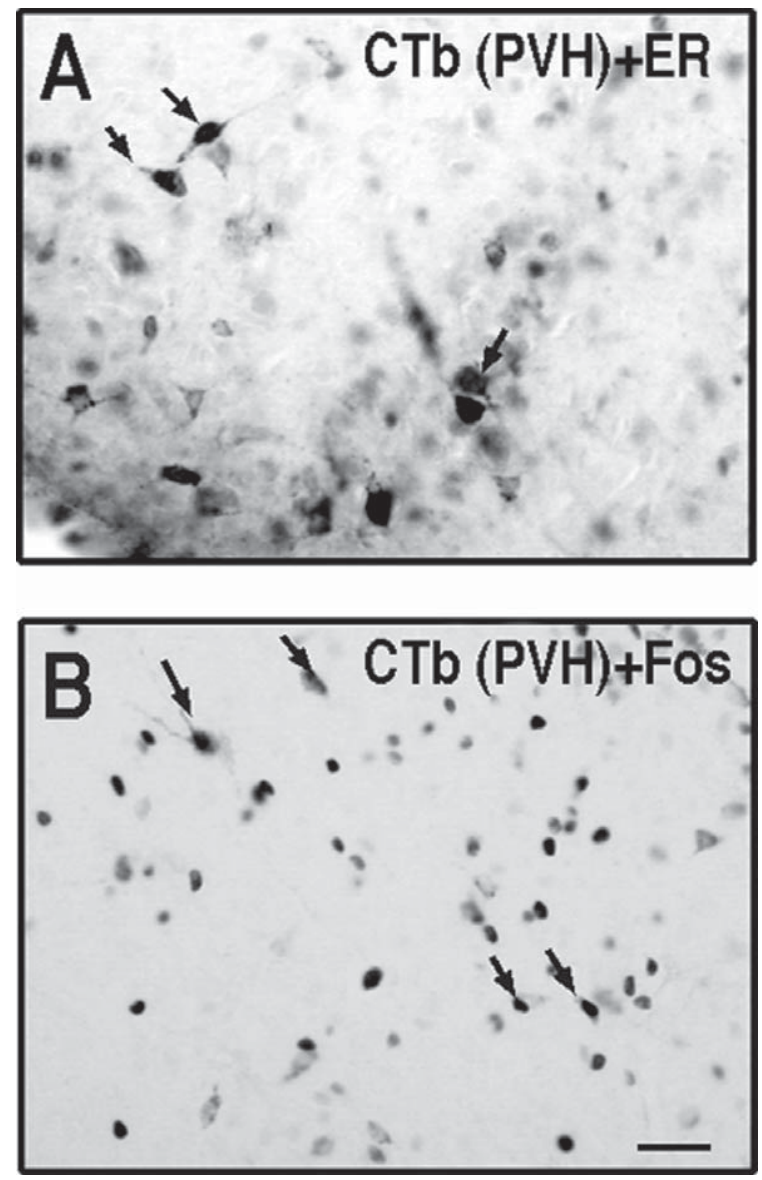

Fig. 6. ER containing neurons in the medial amygdaloid nucleus which project to the paraventricular hypothalamic nucleus and react to stress. CTb was injected iontophoretically to the paraventricular hypothalamic nucleus (PVH) of adult female Wistar rats based on coordinates from a rat brain atlats [23]. After 7 days, the rats were exposed to IMO. The brains were fixed, followed by immunohistochemical detection of $\mathrm{ER} \alpha$ (anti ER $\alpha$, rabbit, No. 409 provided by Dr. Hayashi S, Tokyo Metropolitan Institute for Neuroscience, Japan, diluted 1:20,000), CTb and c-Fos. (A) The arrows indicate co-localization of $\mathrm{CTb}$ and $\mathrm{ER} \alpha$ in the medial amygdaloid nucleus. (B) The arrows indicate co-localization of $\mathrm{CTb}$ and c-Fos in the medial amygdaloid nucleus. Scale bar; $20 \mu \mathrm{m}$ (A, B) (Panels A and $\mathrm{B}$ reprinted from reference 43 with permission).

gest that estrogen treatment could modify the reactivity in these ER-positive and sympathoadrenal-projecting central neurons, thereby decreasing the sympathoadrenal outflow from the central nervous system to the target organs. In fact, estrogen supplementation also reduced IMO-stress induced c-fos mRNA levels in the paraventricular hypothalamic nucleus, the adrenal gland and the heart [42]. These data suggest that estrogen suppresses the stress-induced activation in the central nervous system, the peripheral sympathoadrenal system and the cardiovascular system.

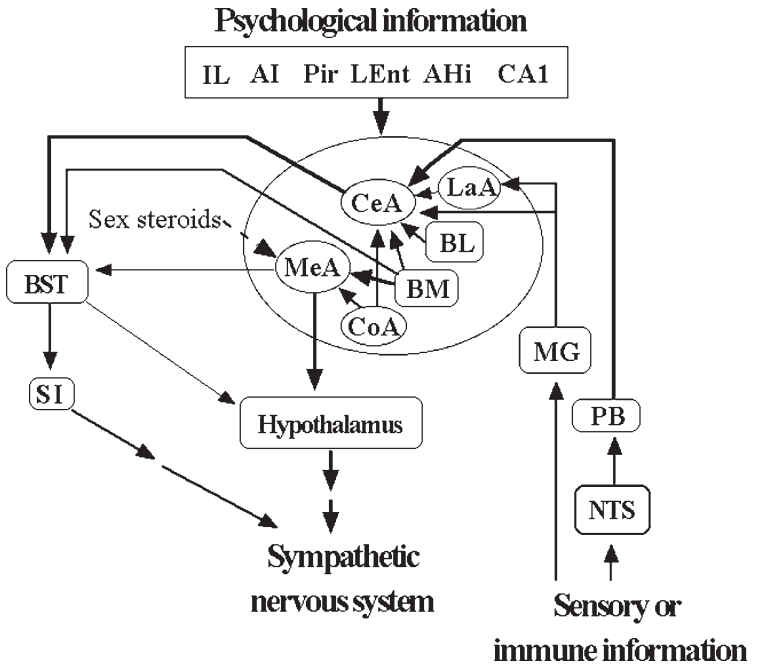

Fig. 7. Summary of this review.

\section{CONCLUSION}

The pathways described in this review are shown in Fig. 7. All amygdaloid subnuclei receive psychological information from other limbic regions, while the lateral and central subnuclei receive peripheral and sensory information from parabachial nucleus and medial geniculate nucleus. Projection to the hypothalamus mainly originates from the medial amygdala, while projection to bed nucleus of the stria terminalis originates from the central nucleus and the medial nucleus. Psychological stress activates mainly the medial amygdala-hypothalamus/bed nucleus of the stria terminalis-sympathetic nervous system, while physical stress or immune challenge activates the central amygdala-bed nucleus of the stria terminalis-the substantia innominate-sympathetic nervous system. Since sex steroid receptors such as ER $\alpha, E R \beta$ and AR are expressed in the medial amygdala, sex steroids, especially estrogen can modulate the sympathetic nervous system activities.

\section{ACKNOWLEDGMENT}

I thank Dr. Arthur D. Loewy (Department of Anatomy and Neurobiology, Washington University School of Medicine, St. Louis, MO, USA) for providing the specimens for the PRV experiments. This paper was in part supported by a Grant-in-Aid from the Ministry of Science and Education of Japan (17590600 and 21590771). 


\section{REFERENCES}

[1] Nance DM, Sanders VM. Autonomic innervation and regulation of the immune system (1987-2007). Brain Behav Immun. 2007; 21: 736

[2] Johnston GR, Webster NR. Cytokines and the immunomodulatory function of the vagus nerve. Br J Anaesth. 2009; 102: 453. doi: 10.1093/bja/aep037.

[3] Hopkins SJ, Rothwell NJ. Cytokines and the nervous system I: Expression and recognition. Trends Neurosci. 1995; 18: 83.

[4] Rothwell NJ, Hopkins SJ. Cytokines and the nervous system II: Actions and mechanisms of action. Trends Neurosci. 1995; 18: 130.

[5] Doenlen R, Krügel U, Wirth T, Riether C, Engler A, Prager G, et al. Electrical activity in rat cortico-limbic structures after single or repeated administration of lipopolysaccharide or staphylococcal enterotoxin B. Proc Biol Sci. 2011; 278(1713): 1864. doi: 10.1098/rspb.2010.2040.

[6] Loewy AD. Viruses as transneuronal tracers for defining neural circuits. Neurosci Biobehav Rev. 1998; 22: 679.

[7] Senba E, Ueyama T. Stress-induced expression of immediate early genes in the brain and peripheral organs of the rat. Neurosci Res. 1997; 29: 183.

[8] Kvetnansky R, Goldstein DS, Weise VK, Holmes C, Szemeredi K, Bagdy G, et al. Effects of handling or immobilization on plasma levels of 3,4-dihydroxyphenylalanine, catecholamines, and metabolites in rats. J Neurochem. 1992; 58: 2296.

[9] Ueyama T, Tanioku T, Nuta J, Kujira K, Ito T, Nakai S, et al. Estrogen alters c-Fos response to immobilization stress in the brain of ovariectomized rats. Brain Res. 2006; 1084: 67

[10] Strack AM, Sawyer WB, Hughes JH, Platt KB, Loewy AD. A general pattern of CNS innervation of the sympathetic outflow demonstrated by transneuronal pseudorabies viral infections. Brain Res. 1989; 491: 156.

[11] Jansen ASP, Farwell DG, Loewy AD. Specificity of pseudorabies virus as a retrograde marker of sympathetic preganglionic neurons: Implications for transneuronal labeling studies. Brain Res. 1993; 617: 103.

[12] Westerhaus MJ, Loewy AD. Central representation of the sympathetic nervous system in the cerebral cortex. Brain Res. 2001; 903: 117.

[13] Krettek JE, Price JL. A description of the amygdaloid complex in the rat and cat with observations on intra-amygdaloid axonal connections. J Comp Neurol. 1978; 178: 255.

[14] Price JL. Subcortical projections from the amygdaloid complex. Adv Exp Med Biol. 1986; 203: 19.

[15] Davis M, Rainnie D, Cassell M. Neurotransmission in the rat amygdala related to fear and anxiety. Trends Neurosci. 1994; 17: 208.

[16] Pitkänen A, Savander V, LeDoux JE. Organization of intraamygdaloid circuitries in the rat: An emerging framework for understanding functions of the amygdala. Trends Neurosci. 1997; 20: 517.

[17] McDonald AJ. Cortical pathways to the mammalian amygdala. Prog Brain Res. 1998; 55: 257.

[18] Swanson LW, Petrovich GD. What is the amygdale? Trends Neurosci. 1998; 21: 323.

[19] Pitkänen A. A connectivity of the rat amygdala complex. In: The Amygdala: A Functional Analysis, edited by Aggleton JP. Oxford, UK: Oxford Univ. Press; 2000: p31.

[20] Sah P, Faber ES, Lopez De Armentia M, Power J. The amygdaloid complex: Anatomy and physiology. Physiol Rev. 2003; 83: 803.
[21] Knapska E, Radwanska K, Werka T, Kaczmarek L. Functional internal complexity of amygdala: Focus on gene activity mapping after behavioral training and drugs of abuse. Physiol Rev. 2007; 87: 1113 .

[22] Engler H, Doenlen R, Engler A, Riether C, Prager G, Niemi $\mathrm{MB}$, et al. Acute amygdaloid response to systemic inflammation. Brain Behav Immun. 2011; 25(7): 1384-1392. doi: 10.1016/j.bbi.2011.04.005.

[23] Paxinos G, Watson C. The Rat Brain in Stereotactic Coordinates. 4th Edition, Academic Press, San Diego. 1998.

[24] Dayas CV, Buller KM, Crane JW, Xu Y, Day TA. Stressor categorization: Acute physical and psychological stressors elicit distinctive recruitment patterns in the amygdala and in medullary noradrenergic cell groups. Eur J Neurosci. 2001; 14: 1143.

[25] Buller KM, Allen T, Wilson LD, Munro F, Day TA. A critical role for the parabrachial nucleus in generating central nervous system responses elicited by a systemic immune challenge. J Neuroimmunol. 2004; 152: 20.

[26] Canteras NS, Simerly RB, Swanson LW. Organization of projections from the medial nucleus of the amygdala: A PHAL study in the rat. J Comp Neurol. 1995; 360(2): 213.

[27] Pardo-Bellver C, Cádiz-Moretti B, Novejarque A, MartínezGarcía F, Lanuza E. Differential efferent projections of the anterior, posteroventral, and posterodorsal subdivisions of the medial amygdala in mice. Front Neuroanat. 2012; 6: 33. doi: 10.3389/fnana.2012.00033.

[28] Sun N, Roberts L, Cassell MD. Rat central amygdaloid nucleus projections to the bed nucleus of the stria terminalis. Brain Res Bull. 1991; 27: 651.

[29] Dong HW, Petrovich GD, Swanson LW. Topography of projections from amygdala to bed nuclei of the stria terminalis. Brain Res Rev. 2001; 38: 192.

[30] Shin JW, Geerling JC, Loewy AD. Inputs to the ventrolateral bed nucleus of the stria terminalis. J Comp Neurol. 2008; 511: 628. doi: 10.1002/cne.21870.

[31] Dong HW, Petrovich GD, Watts AG, Swanson LW. Basic organization of projections from the oval and fusiform nuclei of the bed nuclei of the stria terminalis in adult rat brain. $\mathbf{J}$ Comp Neurol. 2001; 436: 430.

[32] Xu Y, Day TA, Buller KM. The central amygdala modulates hypothalamic-pituitary-adrenal axis responses to systemic interleukin-1beta administration. Neuroscience. 1999; 94: 175.

[33] Mendelsohn ME, Karas RH. The protective effects of estrogen on the cardiovascular system. N Engl J Med. 1999; 340: 1801.

[34] Shughrue PJ, Lane MV, Merchenthaler I. Comparative distribution of estrogen receptor- $\alpha$ and $-\beta$ mRNA in the rat central nervous system. J Comp Neurol. 1997; 388: 507.

[35] Shughrue PJ, Merchenthaler I. Distribution of estrogen receptor $\beta$ immunoreactivity in the rat central nervous system. J Comp Neurol. 2001; 436: 64.

[36] DonCarlos LL, Garcia-Ovejero D, Sarkey S, Garcia-Segura LM, Azcoitia I. Androgen receptor immunoreactivity in forebrain axons and dendrites in the rat. Endocrinology. 3632; 2003: 144.

[37] Cooke BM. Steroid-dependent plasticity in the medial amygdala. Neuroscience. 2006; 138: 997.

[38] He XR, Wang W, Crofton JT, Share L. Effects of 17betaestradiol on the baroreflex control of sympathetic activity in conscious ovariectomized rats. Am J Physiol. 1999; 275: R493.

[39] Vongpatanasin W, Tuncel M, Mansour Y, Arbique D, Victor RG. Transdermal estrogen replacement therapy decreases 
sympathetic activity in postmenopausal women. Circulation. 2001; 103: 2903.

[40] Rachman IM, Unnerstall JR, Pfaff DW, Cohen RS. Estrogen alters behavior and forebrain c-fos expression in ovariectomized rats subjected to the forced swim test. Proc Natl Acad Sci USA. 1998; 95: 13941

[41] Dayas CV, Xu Y, Buller KM, Day TA. Effects of chronic oestrogen replacement on stress-induced activation of hypothalamic-pituitary-adrenal axis control pathways. J Neuroendocrinol. 2000; 12: 784.
[42] Ueyama T, Ishikura F, Matsuda A, Asanuma T, Ueda K, Ichinose M. et al. Chronic estrogen supplementation following ovariectomy improves the emotional stress-induced cardiovascular responses by indirect action on the nervous system and by direct action on the heart. Circ J. 2007; 71: 565.

[43] Ueyama T. Central autonomic nervous system. Bunshi Seishin Igaku (Molecular Psychiatrics). 2011; 11: 8. In Japanese

[44] Ueyama T. Emotion, amygdala, and autonomic nervous system. Brain Nerve. 2012; 64: 1113. In Japanese 